\title{
Acceleration of boiling in the desired conditions: application of its effect in the refinery and petrochemical industries
}

\author{
A. A. Ali ${ }^{1}$, R. Z. Magaril ${ }^{1}$, M. S. Rogalev ${ }^{2}$ \& E. R. Magaril ${ }^{3}$ \\ ${ }^{1}$ Tyumen State Oil and Gas University, Russia \\ ${ }^{2}$ LLC TyumenNIIgiprogas, OJSC “Gazprom”, Russia \\ ${ }^{3}$ Ural Federal University, Russia
}

\begin{abstract}
Rectification is used in almost all the processes of refinery and petrochemical industries. In most cases light fractions or individual components in the bottom of rectification towers are significantly higher than the thermodynamic equilibrium. The reason for this is that in the specified heat supply to the distillation residue of the fractionating tower and its specific volume, the boil-up rate of the light fractions or of some hydrocarbons is lower than the required value. The authors prove that the injection of the surface active agent in a feed stream of the fractionating tower in optimal concentration aimed at the potential content of the bottom product doubles the boiling rate of the residual light fractions in the distillation residue of the fractionating tower. It reduces the residual content of the light components in the bottom of rectification towers and improves quality of the previous fraction. The described effect has an industrial approbation. The result can be used in the running of fractionating towers for various purposes.

Keywords: refinery industry, petrochemical industry, rectification, process of mass transfer, surfactants.
\end{abstract}

\section{Introduction}

Rectification process is widely used in oil refining and hydrocarbon processing industries [1-7]. The process is used while primary crude oil and gas processing for straight-run fractions or the individual components which are further used as a raw material for motor fuel or in the oil refining industry [6]. The rectification process is also very important for stabilization of the end products [3]. 
The theory and sphere of usage of the rectification process in the refining and hydrocarbon processing industries are described in the detailed in the following papers [1-7].

The degree of the distillate take off from the potential content is very important in the work of the rectification columns of various purposes [1, 2, 5]. For example, for atmospheric distillation of oil to light fractions the acceptable is light distillates take off from the potential content at the level of $88-92 \%$ [6]. For stabilizer columns the acceptable is loss of the distillate with the bottom product at the level not more than $5 \%$ [3].

Today losses of distillate with the bottom product of the rectification column is reducing by increasing the percent of the distillate in the inlet stream of the unit or by increase of the operating temperature of bottom [1-7]. These ways of reducing the losses of the distillate with the bottom product are mainly applicable for review of the full rectification column operation. It is for example applicable for operation of the stabilizer columns. Some rectification columns have limits of the heating temperature of feed stream and operating temperature of the bottom parts [3-7]. The limits are normally determined by the thermal destruction temperature of the components of the feed stream of the rectification column. The example of such rectification columns are atmospheric distillation columns of oil and regeneration of water saturated glycol columns of the Integrated Gas Processing Units. The proposals for reduction of the distillate losses given in the scientific and technical literature $[4,6,7]$ for the rectification columns do not provide the significant efficiency improvement of the bottom part of the units.

The existing losses of the distillate with the bottom product of the rectification columns is related to the considerable excess of the thermodynamic equilibrium content of the light weight components in it $[1,2]$. It is caused by insufficient volume of the bottom part of the rectification column and boil-up rates of the components which must be transferred to distillate [2]. The excess of the distillate in the bottom product of the rectification column reduces the quality of the product and have negative impact on the material balance in the refinery and hydrocarbon processing companies [1-7].

So it is a very important issue to develop the ways of reducing losses of the distillate with the bottom product of the rectification columns not related to stiffening of the temperature conditions.

A factor analysis influencing the efficiency of the bottom part of the rectification column is presented in the paper. A way of the operations efficiency improvement without temperature conditions change is proposed. The results of the laboratory surveys and pilot testing of the proposed solutions are given.

\section{Theoretical part}

The authors made an analysis of the bottom part of the unit for selecting the alternative way of reducing the distillate losses with the bottom product in the rectification column.

The efficiency of the bottom part of the rectification column can be defined by the number of the distillate components which penetrate into this part of the unit, 
by the residence time of the bottom product, boil-up rate of the distillate components and heat supply intensity $[1-3,5]$. A set of the specified indicators characterizes a degree of approximation of the distillate content in the bottom product of the rectification column to the thermodynamically equilibrium [2].

Number of the distillate components penetrating into the bottom part of the rectification column depends on the percent of distillation at the unit entry $[1-3,5]$. The indicator is defined by the temperature of the feed stream entry. In many cases the temperature of the feed stream entry is close to the maximum acceptable value provided by the process procedure [6].

The period of the bottom product residence in the bottom part of the rectification column is defined the capacity of the unit and its geometry parameters $[3,5]$.

The intensity of the heat supply to the bottom product of the rectification column is defined by the characteristics of the used heating equipment $[5,6]$. In some cases the temperature of the bottom of the rectification column may be significantly increased [3].

The boil-up rate of the distillate components from the bottom product depend on the thermal-physical properties (latent hear of vaporization, boundary tension between fluid and vapour phases) and the intensity of heat supply to the bottom of the rectification column.

Based on the above the efficiency of the bottom part of the rectification column is mainly characterized by the boil-up rate of the distillation components from the fluid volume in this part of the unit. The boil-up rate of the distillation components is defined by the heat balance of the bottom part of the rectification column.

For a more detailed analysis of the dependency of the boil-up rate of the distillation components from the bottom part of the rectification column on the heat supply the following heat balance equilibrium shall be considered:

$$
Q=Q_{1}+Q_{2}
$$

where: $Q$ - heat amount supplied to the liquid volume in the bottom part of the rectification column per a time unit; $Q_{1}$ - heat amount needed for boil-up of the distillation components per a time unit; $Q_{2}$ - heat amount needed for vapor phase bubbles in the liquid volume (vapor-liquid interface).

Based on the data given in $[5,8]$ the heat amount needed for boil-up of the distillation components from the liquid volume in the bottom part of the rectification column per a unit time may be described as follows

$$
Q_{1}=G \cdot \lambda
$$

where: $G$ - number of the distillate components boiling-up from the bottom part of the unit per a time unit; $\lambda$ - latent heat of vaporization of the distillation components.

Heat amount used for vapor phase bubbles in the liquid volume [9] (interface of vapor and liquid phases), may be described as follows

$$
Q_{2}=\sigma \cdot S
$$


where: $\sigma$ - interfacial tension between liquid and vapor phases in the liquid volume; $S$ - total surface area of the bubbles of vapor phase in the liquid volume.

With regard to formulas (2) and (3) distillate boil-up rate from the liquid volume in the bottom part of the rectification column which is characterized by its mass flow per a time unit, based on the formula (1) may be expressed as follows:

$$
G=\frac{Q-\sigma \cdot S}{\lambda}
$$

The expression (4) proves that the distillate boil-up rate in the bottom part of the rectification column is defined by the intensity of heat supply to the bottom part of the unit and by the thermal-physical properties of the distillate (latent heat of vaporization, boundary tension between liquid and vapor phases). The expression shows that boil-up of the distillation components may be accelerated by the reduction of the boundary tension between liquid and vapor phases in case of no possibility of increasing the temperature of the bottom part of the rectification column.

A way of gas-liquid interfacial tension reduction by injection of a surfactant is proposed in the papers $[10,11]$. Nickel sulphate of synthetic fatty acid $\mathrm{Ni}(\mathrm{RCOO})_{2}$ (where $\mathrm{R}=\mathrm{C}_{9} \div \mathrm{C}_{15}$ ) was used as a surface active agent. Feeding of a surfactant in the amount not more than $50 \mathrm{ppm}$ into the liquid volume reduces its interfacial tension with the air by $50 \%$. The testing results by the example of the systems glycol-air, n-hexane-air, oil-air and straight-run petrol-air are presented.

In the paper the authors will examine the influence of the surfactant $\left(\mathrm{Ni}(\mathrm{RCOO})_{2}\right)$ on the boiling process.

\section{The results of the laboratory tests on the influence of surfactants on the boiling process}

The authors made a set of the laboratory surveys on study of the influence of the surfactants on the boiling process to assess the accuracy of the analytical surveys and the applicability of the conclusions made on the basis of the expression (4), for improving the efficiency of the bottom part of the rectification column.

The laboratory surveys were bases on the hydrocarbon fluids distillation with and without surfactants at the controlled heat supply to its volume. The goal of the distillations was definition and comparison of the boil-up rate of the components from the liquid volume with and without surfactants.

The influence of the surfactants on the boil-up rate of the individual hydrocarbons from the specific volume of the liquid phase and low-boiling components from the binary and multi-component mixtures were considered while the laboratory surveys.

Adding of a surfactant $\mathrm{Ni}(\mathrm{RCOO})_{2}$ reduced the interfacial tension.

The optimum concentration of $\mathrm{Ni}(\mathrm{RCOO})_{2}$ was defined on the basis of the results of surveys on definition of the maximum reduction of the liquid-air interfacial tension at the temperature of $20^{\circ} \mathrm{C}$. 
N-hexane, cyclohehane and benzol are used as individual hydrocarbons. Distillation was made from the flask put into the thermostat. Use of the thermostat ensured the heat supply. The distillation temperature was maintained at the level of $6^{\circ} \mathrm{C}$ higher than the boiling point of the individual hydrocarbons. The distillation time in each case was 30 minutes. The survey results can be seen at the Table 1.

Glycol mixtures with 5\% wt. water were used as binary mixtures. The distillation was also made with use of the thermostat. The distillation temperature was maintained at the level of $140^{\circ} \mathrm{C}$. The distillation for each binary mixture was performed to the residual content of water in the glycol at the level of $1 \% \mathrm{wt}$. The survey results are shown in the Table 2.

Shaim oil and its straight run gasoline (TBP-180OC) was used as a multicomponent mixture. The distillation was made as per the Engler test up to $100^{\circ} \mathrm{C}$. The intensity of heat supply while the distillation of the named multi-component mixtures with the surfactant was similar to the distillation without the surfactant. The survey results are shown in the Table 3.

Table 1: Data on influence of the surfactant on the boil-up rate of the hydrocarbon units from the liquid phase.

\begin{tabular}{|c|c|c|c|c|c|c|c|}
\hline \multirow{2}{*}{$\begin{array}{c}\text { Name of } \\
\text { hydrocarbon }\end{array}$} & \multirow{2}{*}{ 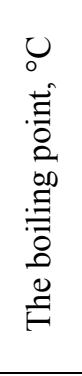 } & \multirow{2}{*}{  } & \multirow{2}{*}{ 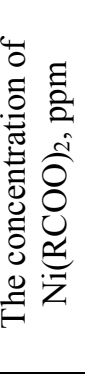 } & \multicolumn{2}{|c|}{$\begin{array}{c}\text { The surface } \\
\text { tension at the } \\
\text { hydrocarbon-air } \\
\text { interface at } 20^{\circ} \mathrm{C} \text {, } \\
\mathrm{mN} / \mathrm{m}\end{array}$} & \multicolumn{2}{|c|}{$\begin{array}{l}\text { The relative rate of } \\
\text { boiling of } \\
\text { hydrocarbon, } \\
\text { units }\end{array}$} \\
\hline & & & & 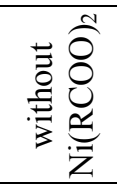 &  & 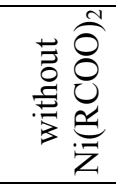 & 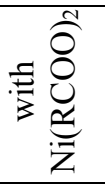 \\
\hline \multirow{3}{*}{ N-hexane } & 68.74 & 75.00 & 5.0 & 18.49 & 13.84 & 1.00 & 1.85 \\
\hline & 68.74 & 75.00 & 10.0 & 18.49 & 11.61 & 1.00 & 2.58 \\
\hline & 68.74 & 75.00 & 15.0 & 18.49 & 14.68 & 1.00 & 1.63 \\
\hline \multirow{3}{*}{ Cyclohexane } & 82.98 & 89.00 & 5.0 & 26.57 & 18.18 & 1.00 & 1.43 \\
\hline & 82.98 & 89.00 & 10.0 & 26.57 & 16.91 & 1.00 & 2.34 \\
\hline & 82.98 & 89.00 & 15.0 & 26.57 & 20.67 & 1.00 & 1.68 \\
\hline \multirow{3}{*}{ Benzol } & 80.10 & 86.00 & 5.0 & 28.84 & 21.19 & 1.00 & 1.69 \\
\hline & 80.10 & 86.00 & 10.0 & 28.84 & 18.73 & 1.00 & 2.10 \\
\hline & 80.10 & 86.00 & 15.0 & 28.84 & 23.67 & 1.00 & 1.35 \\
\hline
\end{tabular}


Table 2: The results of survey on influence of the surfactant on the boiling-up rate of the low-boiling component from the binary mixture (glycol-water).

\begin{tabular}{|c|c|c|c|c|c|c|c|}
\hline \multirow{2}{*}{ 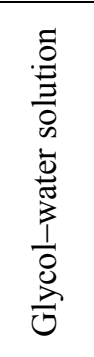 } & \multirow{2}{*}{ 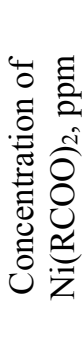 } & \multicolumn{2}{|c|}{$\begin{array}{c}\text { Nater concentration } \\
\text { in the glycol-water } \\
\text { solution, } \\
\% \text { of volume }\end{array}$} & \multicolumn{2}{|c|}{$\begin{array}{l}\text { The surface tension at } \\
\text { the glycol-air interface } \\
\text { at } 20^{\circ} \mathrm{C}, \mathrm{mN} / \mathrm{m}\end{array}$} & \multicolumn{2}{|c|}{$\begin{array}{c}\text { Relative rate of } \\
\text { hydrocarbon } \\
\text { boiling, unit }\end{array}$} \\
\hline & & 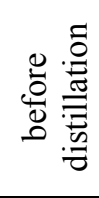 & 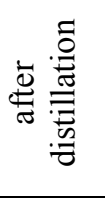 & 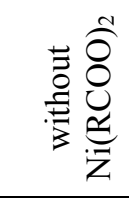 & 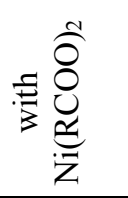 & 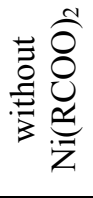 & 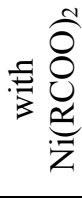 \\
\hline \multirow{3}{*}{$\begin{array}{l}\text { DEG- } \\
\text { water }\end{array}$} & 20 & 5.0 & 1.0 & 48.19 & 29.87 & 1.00 & 1.84 \\
\hline & 25 & 5.0 & 1.0 & 48.19 & 28.67 & 1.00 & 2.01 \\
\hline & 30 & 5.0 & 1.0 & 48.19 & 30.07 & 1.00 & 1.78 \\
\hline \multirow{3}{*}{$\begin{array}{l}\text { TEG- } \\
\text { water }\end{array}$} & 20 & 5.0 & 1.0 & 44.82 & 27.18 & 1.00 & 1.89 \\
\hline & 25 & 5.0 & 1.0 & 44.82 & 26.14 & 1.00 & 2.04 \\
\hline & 30 & 5.0 & 1.0 & 44.82 & 27.34 & 1.00 & 1.82 \\
\hline
\end{tabular}

Table 3: Survey results on influence of the surfactant on boiling rate of low-boiling components by distillation on Engler's method.

\begin{tabular}{|c|c|c|c|}
\hline \multirow{2}{*}{$\begin{array}{c}\text { The } \\
\text { hydrocarbonaceous } \\
\text { liquid }\end{array}$} & \multirow{2}{*}{\begin{tabular}{|c|} 
The \\
concentration \\
of $\mathrm{Ni}(\mathrm{RCOO})_{2}$, \\
ppm
\end{tabular}} & \multicolumn{2}{|c|}{$\begin{array}{l}\text { The relative rate of low-boiling } \\
\text { components, unit }\end{array}$} \\
\hline & & without $\mathrm{Ni}(\mathrm{RCOO})_{2}$ & with $\mathrm{Ni}(\mathrm{RCOO})_{2}$ \\
\hline \multirow{3}{*}{$\begin{array}{c}\text { Straight-run } \\
\text { gasoline fraction } \\
\left(\mathrm{TBP}-180^{\circ} \mathrm{C}\right)\end{array}$} & 7.00 & 1.00 & 1.76 \\
\hline & 9.25 & 1.00 & 2.06 \\
\hline & 12.00 & 1.00 & 1.62 \\
\hline \multirow{3}{*}{ Shaim oil } & 32.00 & 1.00 & 1.82 \\
\hline & 37.75 & 1.00 & 2.15 \\
\hline & 43.00 & 1.00 & 1.76 \\
\hline
\end{tabular}

The laboratory results shown in the Tables $1-3$ show that the reduction of the vapor-liquid interfacial tension ensure increase of the boil-up rate of the individual hydrocarbons from the liquid phase and low-boiling components from the binary and multi-component mixtures at a regular heat supply. It happens as a result of reduction of heat needed for bubbles formation in the liquid volume (vapor-liquid phase interface tension). Use of $\mathrm{Ni}(\mathrm{RCOO})_{2}$ as a surfactant in the optimum concentration lead to two fold increase (on an average) of boil-up rate of the hydrocarbon components. 


\section{The results of pilot testing of the influence of surface active agents on the boiling process}

The determined effect of boil-up rate increase of the hydrocarbon components at the regular heat supply with the surfactant was inspected by the authors within the pilot testing of the rectification columns where there is no possibility of increasing the bottom temperature higher that the definite value. As it was stated before the example of such rectification columns is atmospheric distillation and regeneration of water saturated glycol columns.

Nickel sulfate of synthetic fatty acid $\mathrm{Ni}(\mathrm{RCOO})_{2}$ was used as a surfactant while the pilot testing.

A surfactant was injected into the feed stream of the rectification column in the concentration calculated for the potential content of the bottom product. $\mathrm{Ni}(\mathrm{RCOO})_{2}$ concentration for the atmospheric distillation column was $37.75 \mathrm{ppm}$ and for the regeneration of water saturated glycol column it was $25 \mathrm{ppm}$.

The process parameters of the rectification columns were kept constant while the pilot testing.

Assessment of the surfactant on the boil-up rate of light fractions of oil from the mazut in the bottom part of the atmospheric column was made upon alteration of the selection of the light fractions from the potential oil content.

Assessment of the influence of the surfactant on the boil-up rate of water from the glycol in the bottom part of the regeneration column was made upon alteration of the residual water content in the covered absorbent.

The results of the pilot testing are shown in the Tables 4 and 5.

Table 4: The results of the pilot testing on influence of the surfactant in the feed stream on the efficiency of the atmospheric oil distillation column.

\begin{tabular}{|c|c|c|c|}
\hline \multirow{2}{*}{$\begin{array}{l}\text { The name of the } \\
\text { indicator }\end{array}$} & \multicolumn{3}{|c|}{ The value of the indicator } \\
\hline & $\begin{array}{c}\text { The literary } \\
\text { data* }\end{array}$ & $\begin{array}{c}\text { Without } \\
\mathrm{Ni}(\text { RCOO })_{2}\end{array}$ & With $\mathrm{Ni}(\mathrm{RCOO})_{2}$ \\
\hline $\begin{array}{l}\text { Pressure in the } \\
\text { rectification tower, } \\
\mathrm{MPa}\end{array}$ & $>0.15$ & 0.1 & 0.1 \\
\hline $\begin{array}{l}\text { Temperature of } \\
\text { input raw } \\
\text { material, }{ }^{\circ} \mathrm{C}\end{array}$ & $>360$ & 350 & 350 \\
\hline $\begin{array}{l}\text { The temperature in } \\
\text { the bottom part, }{ }^{\circ} \mathrm{C}\end{array}$ & $>360$ & 338 & 336 \\
\hline $\begin{array}{l}\text { Selection of light } \\
\text { fractions of } \\
\text { potential content in } \\
\text { raw materials, } \\
\% \text { wt. }\end{array}$ & $88 \div 92$ & 93.2 & 97.7 \\
\hline
\end{tabular}

*The literature data taken from [6]. 
Table 5: The results of pilot testing on influence of the surfactant in the rich glycol on the efficiency of the regeneration column.

\begin{tabular}{|c|c|c|c|}
\hline \multirow{2}{*}{ The name of the indicator } & \multicolumn{3}{|c|}{ The value of the indicator } \\
\cline { 2 - 4 } & $\begin{array}{c}\text { The literary } \\
\text { data* }\end{array}$ & $\begin{array}{c}\text { Without } \\
\mathrm{Ni}(\mathrm{RCOO})_{2}\end{array}$ & $\begin{array}{c}\text { With } \\
\mathrm{Ni}(\mathrm{RCOO})_{2}\end{array}$ \\
\hline $\begin{array}{l}\text { Pressure in the } \\
\text { rectification tower, } \mathrm{MPa}\end{array}$ & $>0.11$ & 0.10 & 0.10 \\
\hline Temperature, ${ }^{\circ} \mathrm{C}:$ & $>90$ & 81 & 80 \\
\hline Top & $>140$ & 132 & 133 \\
\hline Raw material input & $>164$ & 155 & 155 \\
\hline Bottom part & & & \\
\hline $\begin{array}{l}\text { Glycol concentration, } \\
\text { wt. }\end{array}$ & $91 \div 97$ & 94.1 & 93.6 \\
\hline Rich absorbent & $>97.5$ & 97.6 & 99.4 \\
\hline Regenerated absorbent & & & \\
\hline
\end{tabular}

*The literature data taken from [7].

The results of the pilot testing of the atmospheric and water saturated glycol regeneration columns shown in the tables 4 and 5 prove the correctness of the decisions made while the analytical and laboratory surveys on increase of the boil-up distillation temperature from the bottom part of the rectification column in the presence of the surfactant. Input of the optimal concentration of $\mathrm{Ni}(\mathrm{RCOO})_{2}$ surfactant into the feed stream of the rectification column, calculated for the potential content of the bottom product, ensured $4.5 \% \mathrm{wt}$. increase of the light fractions from the potential content of oil while its atmospheric distillation (table 4) and allows obtaining the regenerated absorbent with the glycol concentration at the level of $99.4 \% \mathrm{wt}$. (table 5). The temperature of the unit remains the same in each of the reviewed cases. The presence of the surfactant in the bottom product of the considered rectification columns allows significantly improve the purity of the bottom product vs. the values of the optimum distillation content which are given in the scientific and technical literature $[6,7]$.

\section{Conclusion}

In the paper the authors showed that the losses of the distillate with the bottom product of the rectification column of various purposes may be significantly reduced while performance of the process at the presence of surfactants in the feed stream of the units. Selection of the concentration of the surfactant in the feed stream of the rectification column must be performed on the basis of the surveys on influence of the bottom product on the interfacial tension with air. Input of the definite concentration of the surfactant into the feed stream of the rectification column is recommended from the point of the potential content of the bottom product. Use of nickel sulfate of the synthetic fatty acid $\mathrm{Ni}(\mathrm{RCOO})_{2}$ (where $\mathrm{R}=\mathrm{C}_{9} \div \mathrm{C}_{15}$ ) as a surfactant is shown for the rectification process. 
Use of the surfactant in the rectification process increases the boil-up rate of the distillation components from the bottom product in the lower part of the unit two times on an average. It is explained by reduction of some heat spent for vapor-liquid interfacial tension in the bottom part of the unit and facilitating of the distillate components transfer from the liquid to vapor phase as a result of reduction of vapor-liquid interfacial tension. The effect from the presence of the surfactant in the liquid volume of the bottom part of the rectification column makes the process of the distillate boil-up close to the thermo-dynamic equilibrium at a definite time of mixture presence in the bottom part of the unit and a definite heat volume supply.

Implementation of the proposed engineering solution into the operation of the rectification columns will ensure considerable reduction of the distillate losses with the bottom product. It will make the material balances of refining and hydrocarbon processing companies close to the design parameters and will reduce the by-products of many processes.

\section{References}

[1] Kafarov, V.V. Fundamentals of mass transfer, [in Russian], second edition processing, High School: Moscow, 1972.

[2] Bagaturov S.A. The theory and calculation of distillation and rectification, [in Russian], third edition revised, Chemistry: Moscow, 1974.

[3] Aleksandrov I.A. Distillation and rectification in refining, [in Russian], Chemistry: Moscow, 1981.

[4] Berlin, A.M., Gorechenkov, V.G., Volkov, N.P. Processing of oil and natural gases, [in Russian], Chemistry: Moscow, 1981.

[5] Skoblo A.I., Molokanov Yu. K, Vladimirov A.I. Processes and equipment for refineries and petrochemical plants, [in Russian], third edition revised and expanded, LLC "Nedra - business-center": Moscow, 2000.

[6] Manovjan A.K. Technology of primary processing of oil and natural gas, [in Russian], second edition, Chemistry: Moscow, 2001.

[7] Gritsenko, A.I., Istomin, V.A., Kulkov, A.N., Sulemanov, R.S. Gathering and conditioning of gas on the northern gas fields of Russia, [in Russian], Nedra: Moscow, 1999.

[8] Dgankoli D. Physics, [in Russian], translation from English, Mir: Moscow, 1989.

[9] Frank-Kamenetskii, D.A., Diffusion and Heat Transfer in Chemical Kinetics, [in Russian], Nauka: Moscow, 1987.

[10] Ikanin, S.A., Magaril, R.Z., Improve the process of drying of natural gas [in Russian]. Izvestia vyssih ucebyh zavedenij, Neft I gas: Tyumen, 4, pp. 86-90, 2005.

[11] Rogalev M.S., Magaril, R.Z., Klauzner Sh-G. M. Aspects of the primary distillation of crude oil [in Russian]. Izvestia vyssih ucebyh zavedenij, Neft I gas: Tyumen, 4, pp. 73-78, 2008. 